\title{
Aquisição de pronomes clíticos de português europeu por falantes de chinês: dados sobre a colocação
}

\author{
Wenjun $G u^{l}$ \\ SISU\&CLUNL/NOVA
}

\begin{abstract}
:
This paper presents a pilot-study of a research which aims to investigate the acquisition of the clitic pronouns in European Portuguese (EP) by Chinese learners. Based on an acceptability judgement task, conducted with 20 Chinese students and a control group of 26 native speakers of EP, we would like, on the one hand, to make a better characterization of the development of placement properties of clitic pronouns in Chinese learners' interlanguage grammars; on the other hand, to contribute to a better understanding of the theoretical proposals on the learnability problems regarding uninterpretable features not available in the first language (L1). Our preliminary results suggest that, as shown in previous works on L1 EP and L2 EP, the conditions which determine proclisis seem to be more difficult to acquire than those for enclisis and the different contexts of proclisis seem to develop gradually, following a similar path to that previously described for L1 EP.
\end{abstract}

Keywords: clitic pronoun, placement, second language acquisition, Chinese learners, European Portuguese

Palavras-chave: pronomes clíticos, posição, aquisição de L2, aprendentes chineses, português europeu

\section{Introdução}

A posição dos pronomes clíticos parece ter-se registado, na literatura, como um fenómeno problemático na aquisição do português europeu (PE), quer como língua materna (L1) quer como língua segunda (L2).

$\mathrm{Na}$ esfera da aquisição como L1, observou-se, em PE, um desenvolvimento mais tardio e lento do conhecimento sobre a posição dos clíticos, relativamente ao que acontece em muitas outras línguas românicas. Os estudos efetuados neste âmbito com francês, italiano, espanhol e grego-padrão (Grüter, 2006; Guasti, 1993/1994; Wexler, Gavarró \& Torrens, 2004; Marinis, 2000, etc.) verificaram normalmente colocações-alvo de clíticos por crianças desde fases iniciais. No entanto, em PE, permanecem os problemas na posição de clíticos entre as crianças até aos 7 anos de idade (Costa, Fiéis \& Lobo, 2015). Os dados obtidos em PE como L1 apresentam indícios de: a) um fenómeno de generalização de ênclise nos estádios iniciais (Costa \& Lobo, 2013); b) assimetrias no ritmo da aquisição de colocação de clíticos em diferentes contextos sintáticos, mostrando que, por um lado, os padrões de próclise poderão ser mais difícil e tardiamente adquiridos do que os de ênclise (Duarte, Matos \& Faria, 1995) e, por outro lado, os diferentes contextos de posição proclítica parecem ser desenvolvidos gradualmente, seguindo uma ordem de aquisição sugerida como: negação > sujeito negativo > advérbios (proclisadores) > orações adverbiais finitas > quantificadores (sujeito) (Costa, Fiéis \& Lobo, 2015).

\footnotetext{
${ }^{1} \mathrm{O}$ presente trabalho faz parte de um estudo sobre a aquisição de pronomes clíticos por falantes nativos de chinês, que aprendem o português europeu como língua não materna. Trata-se de um trabalho desenvolvido no âmbito do projeto de doutoramento (No. 201506900058), financiado pelo Conselho das Bolsas de Estudo da China ("China Scholarship Council", CSC), sob a orientação da Professora Doutora Ana Madeira.
} 
No domínio da aquisição como L2, ainda são escassos os estudos que abordam especificamente este tópico, apesar de a posição dos pronomes clíticos em PE ter sido registada como um dos aspetos problemáticos para os aprendentes estrangeiros (Grosso, 1999; Madeira, Crispim \& Xavier, 2006; Madeira \& Xavier, 2009; Mai, 2006; Rosário, 1997, entre outros). Os poucos trabalhos realizados até ao momento disponibilizam principalmente dados de produção induzida escrita (reescrita de frases, preenchimento de espaços, entre outros) ou de juízos de gramaticalidade/aceitabilidade de falantes nativos de línguas românicas (francês, espanhol, catalão e italiano), de línguas germânicas (alemão, inglês, holandês) e urálica (finlandês) (Madeira, Crispim \& Xavier, 2006; Madeira \& Xavier, 2009), para além de alguns dados de produção induzida oral de falantes nativos de chinês (Gu, no prelo). Nestes trabalhos, parecem ter-se indiciado características da aquisição dos padrões de colocação dos clíticos semelhantes às observadas entre as crianças na aquisição de L1, contudo, estes dados, sendo poucos em quantidade, não são suficientes para se desenvolver uma análise mais sistemática e aprofundada sobre o fenómeno, nem para apoiarem, de forma consolidada, as conclusões retiradas nos outros estudos.

A investigação no âmbito da qual o presente estudo se insere tem como objetivo contribuir para o enriquecimento dos dados existentes neste âmbito e, ao mesmo tempo, verificar os resultados obtidos nos estudos anteriores tanto em L1 como em L2. Tendo como grupo-alvo de estudo falantes nativos de chinês mandarim que aprendem o PE como L2, pretende-se realizar um teste-piloto de juízos de aceitabilidade sobre a posição dos pronomes clíticos (acusativos) em PE. Será efetuada uma comparação particular entre os dados de juízos deste estudo e os da produção induzida oral, anteriormente obtidos por Gu (no prelo), trabalho em que se observaram, entre aprendentes chineses, os mesmos fenómenos registados em PE como L1 ou, mais precisamente: a) generalização de ênclise a contextos de próclise, mas com um efeito de desenvolvimento entre os informantes com menos tempo de aprendizagem e aqueles com mais tempo de aprendizagem; e b) assimetrias no desenvolvimento das propriedades de colocação dos clíticos em diferentes contextos, sendo a ênclise adquirida mais cedo do que a próclise e seguindo a aquisição das condições proclíticas um determinado percurso: negação > advérbio > oração subordinada finita > quantificador. Espera-se que os resultados deste trabalho ajudem descrever e caracterizar melhor o desenvolvimento do conhecimento sobre a posição dos pronomes clíticos em PE na interlíngua dos falantes nativos de chinês.

Tendo em conta que se assume ser inexistente, em chinês, a classe de pronomes clíticos e que as propriedades da sua posição estão associadas a traços não interpretáveis, já que estas não afetam a interpretação, espera-se também que o presente trabalho nos ajude a compreender melhor a aquisição de traços não interpretáveis ausentes na L1 dos aprendentes não-nativos.

Serão discutidas duas propostas que defendem hipóteses contraditórias neste âmbito, designadamente a Hipótese de Transferência Plena/Acesso Pleno defendida por Schwartz \& Sprouse (1996) e a Hipótese de Interpretabilidade, sugerida por Tsimpli \& Dimitrakopoulou (2007). Na perspetiva da Hipótese de Transferência Plena/Acesso Pleno, considera-se que "a gramática da L1 é transferida na sua totalidade, correspondendo ao estádio inicial da aquisição da L2, e é reestruturada gradualmente, à medida que o aprendente é exposto a dados da L2 que são incompatíveis com as regras da gramática da sua interlíngua" (Madeira, 2017:315). Presume-se que a reestruturação da gramática ocorre com base na Gramática Universal e, assim, prediz-se que "os falantes não-nativos podem adquirir plenamente todas as propriedades gramaticais da língua-alvo" (Madeira, 2017:315). Por outro lado, a Hipótese de Interpretabilidade propõe que a aquisição da L2 está sujeita a um período crítico e que, após este período, os traços não interpretáveis, se não se encontram originalmente ativados na gramática da L1, deixam de ser acessíveis aos aprendentes, enquanto os traços interpretáveis se mantêm sempre acessíveis. Assim, prevê-se, de acordo com esta hipótese, o insucesso da aquisição de traços não interpretáveis ausentes em L1. 
Este artigo está organizado do seguinte modo: na secção 2, realizar-se-á uma breve descrição das propriedades dos pronomes acusativos em PE e em chinês mandarim; na secção 3, apresentar-se-á o presente estudo com respeito às questões de investigação, ao teste aplicado e às características dos seus participantes; na secção 4, analisar-se-ão os dados obtidos no teste e, finalmente, na seç̧ão 5, discutir-se-ão os resultados enquanto se procura chegar a algumas conclusões preliminares.

\section{Pronomes acusativos em português europeu e em chinês}

A língua portuguesa e a língua chinesa diferenciam-se bastante no que diz respeito às propriedades dos seus pronomes acusativos. Cardinaletti \& Strake (1999) sugeriram uma tripartição na categoria de pronomes pessoais, na qual se distinguem três classes distintas, nomeadamente: pronomes clíticos, pronomes fracos e pronomes fortes, considerando-se os pronomes clíticos e os fracos mais deficientes do que os fortes a nível morfológico, sintático e fonológico. Conforme esta taxonomia e as propriedades assimetricamente encontradas entre as classes, os pronomes clíticos ocorrem apenas em PE, caracterizando-se particularmente pelas seguintes restrições na sua distribuição:

i) Base/ posições- $\theta$

Como descrito por Cardinaletti \& Strake (1999), os pronomes acusativos em PE, sendo pronomes deficientes, não se encontram nas posições temáticas (cf. (1)).

(1) a. O João não viu a Ana. b. O João não a viu.

ii) Posições periféricas

Os pronomes acusativos em PE ocorrem nas posições derivadas, mas não em determinadas posições periféricas, como, por exemplo, nas construções clivadas, nas deslocações esquerdas/direitas ou em isolamento (cf. (2)-(3)).

(2) a. A Ana, o João viu.

b. * $\underline{\text { A }, ~ o ~ J o a ̃ o ~ v i u . ~}$

(3) a. Quem é que o João viu? A Ana.

b. Quem é que o João viu? *A.

iii) C-modificação/coordenação

Não podem ser C-modificados, ou seja, modificados por advérbios que afetam o sintagma nominal total, nem são compatíveis com a coordenação (cf. (4)).

(4) a. O João viu a Ana e a Maria ontem num café.

b. ??O João viu-a e a Maria ontem num café. ${ }^{2}$

Relativamente à língua chinesa, assume-se que se encontram apenas pronomes fortes em posição de complemento direto do verbo, cuja distribuição é semelhante à dos sintagmas nominais plenos, tendo em conta que:

i) Base/ posições- $\theta$

Os pronomes acusativos em chinês são totalmente compatíveis com as posições temáticas (cf. (5)).

${ }^{2}$ Encontra-se variação relativamente aos juízos de aceitabilidade sobre esta frase entre os falantes nativos de PE. 
(5) a. Ruo Ang mei kanjian An Na.

João não ver Ana

O João não viu a Ana.

b. Ruo Ang mei kanjian ta.

João não ver ela

O João não a viu.

ii) Posições periféricas

Tal como os sintagmas nominais, os pronomes acusativos em chinês podem ocorrer nas posições periféricas, o que é impossível para os pronomes deficientes (cf. (6)-(7)).

(6) a. An Na, Ruo Ang kanjian le.

Ana João ver $\mathrm{LE}^{3}$

A Ana, o João viu.

b. Ta, Ruo Ang kanjian le.

Ela João ver LE

*Ela, o João viu.

(7) a. Ruo Ang kanjian shei le? An Na.

João ver quem LE? Ana

Quem é que o João viu? A Ana.

b. Ruo Ang kanjian shei le? Ta.

João ver quem LE? Ela

Quem é que o João viu? *Ela.

iii) C-modificação/coordenação

Também se observou que os pronomes acusativos em chinês podem ser C-modificados ou coordenados (cf. (8)).

(8) a. Zuotian, Ruo Ang kanjian le An Na he Ma Li Ya.

Ontem, João ver LE Ana e Maria

Ontem, o João viu a Ana e a Maria.

b. Zuotian, Ruo Ang kanjian le ta he Ma Li Ya.

Ontem, João ver LE ela e Maria

??Ontem, o João viu-a e a Maria.

No que diz respeito à colocação dos pronomes acusativos, a qual constitui o foco do presente estudo, a língua portuguesa apresenta uma variação muito maior do que a língua chinesa. No caso de PE, podem encontrar-se os pronomes acusativos em posições proclítica, enclítica e mesoclítica, dependendo a sua colocação de contextos sintáticos específicos.

De acordo com Martins (2013), aplica-se a próclise principalmente quando os pronomes acusativos se encontram: a) em orações principais, com o verbo precedido por elementos tais como palavras negativas (cf. (9)), determinados quantificadores (cf. (10)), certos advérbios (cf. (11)), constituintes $Q U$ - (cf. (12)); b) em orações

3 "Le" é um marcador aspetual em chinês, que indica normalmente a conclusão de uma ação. 
subordinadas finitas (cf. (13)); c) em orações infinitivas flexionadas introduzidas por determinadas preposições (cf. (14)). A ênclise (cf. (15)), como a ordem básica, ocorre nos restantes casos em que não se obriga a próclise. ${ }^{4}$

(9) Não nos cumprimentaram.

(10) Alguém o mencionou.

(11) Também $\boldsymbol{a}$ adorei.

(12) Quem vos encontrou?

(13) Sabes que me deito sempre tarde.

(14) Para os impressionarem, têm de organizar o evento muito bem.

(15) O João levanta-se cedo.

Quanto ao chinês, colocam-se os pronomes acusativos principalmente em posição pós-verbal (cf. (17)-(20)); e pré-verbal só em contextos muito restritos, como na construção "ba"5 (cf. (21)).

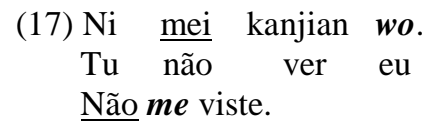

(18) Wo ye taoyan ta. Eu também detestar ele Também o detesto.

(19) Shei zuotian yudao le tamen? Quem ontem encontrar LE eles Quem é que os encontrou ontem?

(20) $\mathrm{An} \mathrm{Na}$ shuo ta renshi $\boldsymbol{n i}$. Ana disse ela conhecer tu A Ana disse que te conhecia.

(21) Zhe xiangzi hen zhong. Ni ba ta fang zheli. Esta caixa muito pesada. Tu $\overline{\mathrm{BA}}$ ela deixar aqui Esta caixa é muito pesada. Deixa-a aqui.

Com base nas considerações acima apresentadas, a aquisição da posição dos pronomes acusativos em PE por falantes nativos de chinês poderá corresponder a um processo em que se constrói uma categoria nova "clítico" inexistente no sistema de pronomes pessoais da L1 dos aprendentes enquanto se ativam e especificam as propriedades desta categoria. Uma vez que todos os pronomes pessoais, quer fortes quer clíticos, partilham

\footnotetext{
${ }^{4}$ A posição mesoclítica ocorre quando os pronomes clíticos se juntam a verbos nas formas do condicional ou do futuro (cf. (i)). Pode ser considerada uma variante da ênclise, uma vez que ocorre nos contextos em que os pronomes deveriam aparecer em ênclise se o verbo não estivesse no futuro ou no condicional (Brito, Duarte \& Matos, 2003).

(i) Convidar-te-ei para a festa.

A mesóclise não foi incluída como objeto do presente estudo, já que se trata de uma forma mais marcada e que é aprendida no contexto de escolarização (Costa 2012, entre outros).

${ }^{5}$ A construção "ba" é um fenómeno específico da língua chinesa, em que uma expressão nominal, sucedente ao elemento "ba", precede o verbo que a seleciona. Trata-se de um fenómeno bastante estudado na linguística chinesa, nomeadamente no que diz respeito à natureza de "ba" e às propriedades desta construção; no entanto, falta um consenso claro até agora acerca desta forma (encontram-se diferentes propostas de análise nos trabalhos de Y.-H. Audrey Li 2006; Huang, Li \& Li 2009, entre outros).
} 
semelhanças na sua referência, a qual está sempre dependente da situação de enunciação ou do contexto linguístico/discursivo (Lobo, 2013: 2193), assume-se que as propriedades semânticas não devem ser problemáticas para os aprendentes chineses na sua aquisição dos pronomes acusativos em PE. $\mathrm{O}$ aspeto fundamental da aquisição reside provavelmente nas propriedades morfossintáticas que são diferentes na L1 e na L2, especialmente as propriedades sintáticas, que se consideram associadas a traços não interpretáveis, e cuja aquisição implicará uma especificação dos padrões de colocação dos pronomes em diversos contextos sintáticos.

\section{Presente estudo}

\subsection{Questões de investigação}

O presente trabalho destina-se a descrever, com base em dados de juízos, o estado da aquisição dos padrões de colocação dos pronomes clíticos acusativos em PE por falantes nativos de chinês. Procura-se averiguar, através de uma análise destes resultados, juntamente com os resultados anteriormente obtidos em outros estudos, as características do desenvolvimento das propriedades-alvo em PE dos aprendentes chineses e até, de alguma forma, as características da sua aquisição por falantes não nativos em geral.

Serão abordadas principalmente as seguintes questões: a) observa-se uma generalização da ênclise nos juízos dos aprendentes chineses de PE como L2? b) mostra-se mais dificuldade na aquisição de próclise do que na de ênclise? c) verificam-se assimetrias no ritmo de desenvolvimento dos padrões proclíticos? d) Se sim, segue-se uma ordem da aquisição semelhante às observadas em outros estudos?

Como apresentado nas secções anteriores, pela ausência dos pronomes clíticos acusativos em chinês e pela suposição da associação entre as propriedades sobre a posição dos pronomes clíticos em português e os traços não interpretáveis, considera-se que a aquisição destas propriedades por aprendentes chineses, adultos, no nosso caso, corresponde a um processo em que se desenvolvem, após o período crítico, traços não interpretáveis de L2, indisponíveis na L1. Tendo em conta as duas propostas acerca da possibilidade da aquisição dos traços não interpretáveis neste âmbito, espera-se que:

$>$ Caso se verifique a Hipótese de Transferência Plena/Acesso Pleno, a aquisição das propriedades, com o acesso pleno à GU, acabará por ser bem-sucedida, i.e., todos os padrões de colocação dos pronomes clíticos de PE poderão ser adquiridos pelos aprendentes chineses.

> Caso se verifique a Hipótese da Interpretabilidade, a colocação dos pronomes clíticos em português permanecerá sempre problemática para os informantes chineses, independentemente do seu tempo da aprendizagem da língua ou do contexto sintático (enclítico ou proclítico) onde se encontram os clíticos.

\subsection{Teste}

Neste trabalho, foi aplicado um teste de juízos de aceitabilidade, inspirado pelo estudo de Madeira \& Xavier (2009) sobre a aquisição de pronomes clíticos em PE por falantes nativos de outras línguas românicas e de línguas germânicas. Através desta tarefa, procura-se avaliar as intuições dos participantes sobre a colocação dos pronomes clíticos. Os dados obtidos nesta tarefa ajudam a integrar informações sobre os conhecimentos dos informantes relativamente às propriedades sintáticas em estudo, tendo em conta que o uso destas propriedades na produção dos participantes nem sempre corresponde ao seu real conhecimento. 
$\mathrm{O}$ teste foi realizado individualmente pelos participantes no computador. Cada item continha uma frase sublinhada, precedida, na maioria dos casos, por um contexto. Pediu-se aos informantes para avaliar se cada frase lhes soava natural e adequada ao contexto (quando aplicável), numa escala de 1 a 5 , sendo "1" completamente não aceitável e "5" completamente aceitável. Seguem-se dois exemplos:

(22) Este vestido é bonito, mas muito caro.

A Lília não o comprou.
$\circ 1$
○ 2
$\circ 3$
$\circ 4$
$\circ 5$

(23) Todas as raparigas arranjaram-se antes da festa.
○ 1
$\circ 2$
$\circ 3$
$\circ 4$
$\circ 5$

Foram testados 5 contextos:

i. orações simples sem nenhum proclisador

ii. orações simples com proclisadores, nomeadamente:
a. negativas (ñ̃o)
b. com um quantificador proclisador (todos)
c. com um advérbio que induz a próclise (também)

iii. orações subordinadas adverbiais causais finitas (porque)

A tarefa contém no total 60 itens de teste, que envolvem colocações-alvo ou desviantes dos pronomes clíticos acusativos de $3^{\mathrm{a}}$ pessoa, reflexos e não reflexos, a par de 36 distratores. Em todas as condições, metade dos clíticos envolvidos eram reflexos e metade eram não-reflexos. Nos itens que se associam aos pronomes clíticos não-reflexos, são sempre utilizados complementos diretos não animados. Cada item aparece duas vezes no teste: uma vez na sua forma canónica e a outra na sua forma desviante (cf. (24)). Isto permite-nos determinar se a rejeição ou aceitação de uma dada frase pode ser atribuída à posição do clítico.

(24) a. Todas as raparigas se arranjaram antes da festa.
$\circ 1$
$\circ 2$
$\circ 3$
$\circ 4$
$\circ 5$ 
b. Todas as raparigas arranjaram-se antes da festa.
$\circ 1$
$\circ 2$
$\circ 3$
$\circ 4$
$\circ 5$

Os itens são apresentados de forma separada, em vez de serem agrupados, a fim de evitar efeitos de preferência.

\subsection{Participantes}

Temos como participantes 20 estudantes chineses, que estavam a estudar em Portugal ${ }^{6}$ e que foram divididos em dois grupos, conforme o seu tempo de aprendizagem de português. Incluímos também 26 informantes portugueses, como controlo. Mostram-se, na tabela seguinte, as características registadas destes participantes.

Tabela 1 - participantes

\begin{tabular}{|c|c|c|c|}
\hline & Grupo 1 & Grupo 2 & Controlos \\
\hline Idade & 19-22 (média $21 ; 2$, dp 0,90 ) & 22-27 (média 24;7, dp 1,28) & 19-48 (média 26;9, dp 8,59 ) \\
\hline $\begin{array}{c}\text { Tempo de } \\
\text { aprendizagem }^{7} \\
\end{array}$ & $\begin{array}{c}<4 \text { anos } \\
\text { (média } 3 ; 5, \text { dp } 0,66)\end{array}$ & $\begin{array}{c}>=4 \text { anos } \\
\text { (média } 6 ; 11, \text { dp } 1,45)\end{array}$ & / \\
\hline L1 & Chinês (mandarim) & Chinês (mandarim) & Português (europeu) \\
\hline Outras L2 & $\begin{array}{l}\text { Inglês }(n=9) ; \\
\text { Coreano }(n=1) ; \\
\text { Japonês }(n=1)\end{array}$ & Inglês $(n=8)$; & $\begin{array}{l}\text { Alemão }(n=6) ; \\
\text { Espanhol }(n=11) ; \\
\text { Francês }(n=8) ; \\
\text { Inglês }(n=25) ; \\
\text { Italiano }(n=2) ; \\
\text { Chinês }(n=8) \\
\end{array}$ \\
\hline $\begin{array}{c}\text { Número de } \\
\text { participantes }\end{array}$ & 10 & 10 & 26 \\
\hline
\end{tabular}

\section{4. $\quad$ Resultados}

Os resultados médios globais são apresentados na tabela 2:

\footnotetext{
${ }^{6}$ Como sugerido por um/a revisor/a anónimo/a, é possível que em contextos de oralidade informal estes aprendentes sejam expostos a uso de ênclise em contextos de próclise, conforme observado em vários estudos anteriores com falantes nativos de PE (Santos 2002, entre outros).

${ }^{7}$ Gostaríamos de ter incluído alunos chineses que se encontrassem em fase relativamente inicial de português, com ainda menos tempo de aprendizagem, mas por razões práticas, tal acabou por não ser possível no momento de aplicação do teste.
} 
Tabela 2 - Média das pontuações (Ênclise vs. Próclise)

\begin{tabular}{|c|c|c|c|c|}
\hline \multirow{2}{*}{} & \multicolumn{2}{|c|}{ Contexto enclítico } & \multicolumn{2}{c|}{ Contexto proclítico } \\
\cline { 2 - 5 } & Ênclise & Próclise & Enclise & Próclise \\
\hline Grupo 1 & 4,32 & 2,85 & 2,43 & 4,00 \\
\hline Grupo 2 & 4,25 & 2,37 & 2,33 & 3,98 \\
\hline Controlo & 4,82 & 2,12 & 2,64 & 4,56 \\
\hline
\end{tabular}

De um modo geral, todos os participantes conseguiram distinguir as condições que determinam a alternância entre ênclise e próclise, dando pontuações superiores a 4 (com 4 inclusive) às frases em que os pronomes clíticos se encontram em posições apropriadas e pontuações inferiores a 3 às frases com clíticos em posições desviantes.

As taxas de respostas-alvo ${ }^{8}$ dos informantes com respeito aos contextos de ênclise e de próclise em geral são semelhantes, tendo os dois grupos chineses resultados relativamente próximos dos apresentados pelos controlos (Tabela 3). Os falantes nativos de PE parecem mostrar melhor desempenho nos contextos enclíticos do que nos proclíticos (83,01\% vs. 70,67\%), mas esta diferença não foi claramente verificada entre os participantes chineses.

Tabela 3 - Taxas de respostas-alvo (Ênclise vs. Próclise) ${ }^{9}$

\begin{tabular}{|c|c|c|}
\hline & Enclise & Próclise \\
\hline Grupo 1 & $62,50 \%$ & $65,84 \%$ \\
\hline Grupo 2 & $61,67 \%$ & $63,54 \%$ \\
\hline Controlo & $83,01 \%$ & $70,67 \%$ \\
\hline
\end{tabular}

Foram observadas assimetrias no desempenho dos participantes de todos os três grupos relativamente aos itens gramaticais ${ }^{10}$ e aos agramaticais na análise geral das taxas de acerto dos inquiridos (Gráfico 1), os quais parecem manifestar mais dificuldade em identificar as colocações inapropriadas dos clíticos do que as colocações apropriadas.

\footnotetext{
${ }^{8}$ Nas "respostas-alvo", estão incluídos não só os casos de aceitação dos itens gramaticais, mas também os de rejeição dos itens agramaticais. ${ }^{9}$ Neste trabalho, para uma interpretação mais clara das avaliações dos participantes sobre as frases, excluímos sempre as respostas de "3" no cálculo de percentagens.

${ }^{10}$ É verdade que os termos "gramatical" e "agramatical" parecem combinar-se melhor com o caso dos contextos de ênclise do que com os de próclise, já que, no caso de ênclise, o uso da próclise é sempre agramatical; não obstante, no caso de próclise, o uso de ênclise em alguns contextos é aceitável para alguns falantes nativos. Contudo, neste artigo, serão referidos simplesmente como "itens gramaticais" os itens em que os pronomes estão adequadamente colocados, e como "itens agramaticais" aqueles em que os pronomes não se encontram nas posições canónicas de acordo com a norma.
} 


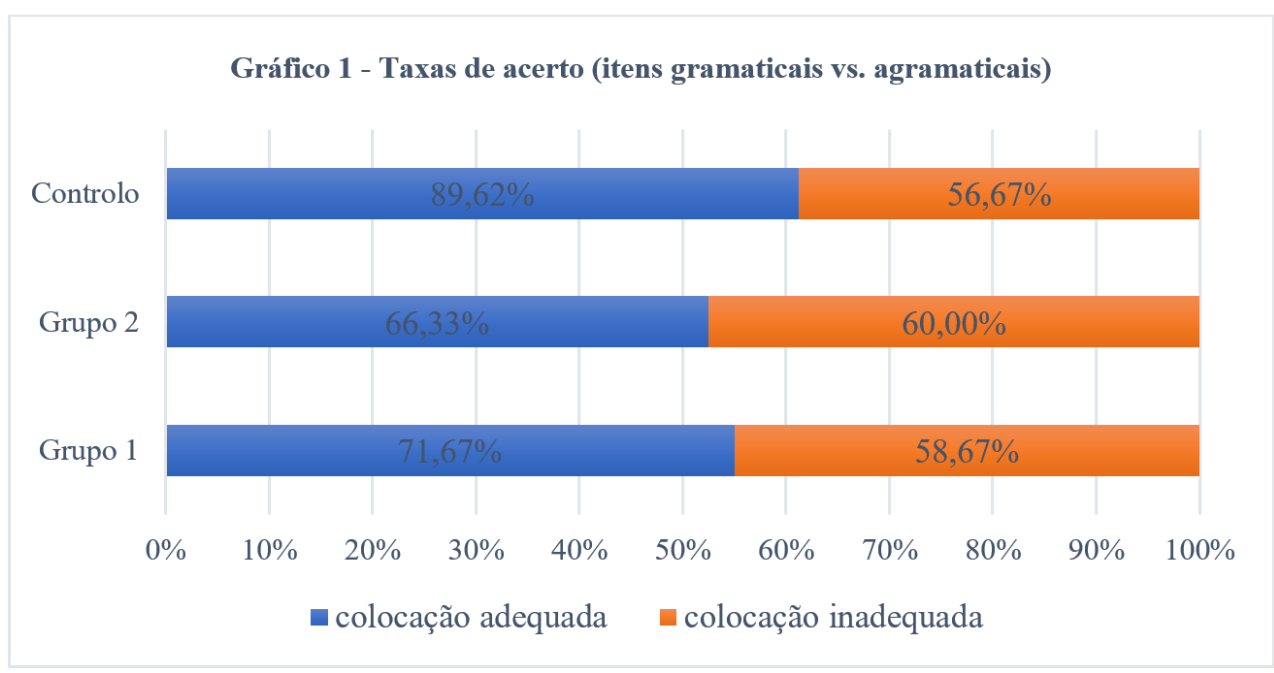

Uma análise mais aprofundada dos resultados (Tabela 4) indica que: a) os participantes chineses, à semelhança dos controlos, apresentam melhor desempenho nos contextos enclíticos do que nos proclíticos nos itens gramaticais; b) os informantes têm melhor desempenho nos itens gramaticais do que nos agramaticais, aliás, este contraste não se mostrou muito bem nos contextos proclíticos entre os grupos chineses como nos outros contextos; c) os controlos apresentam melhor desempenho do que os participantes chineses em todos os contextos, menos nos casos de próclise em que os clíticos se encontram na posição enclítica.

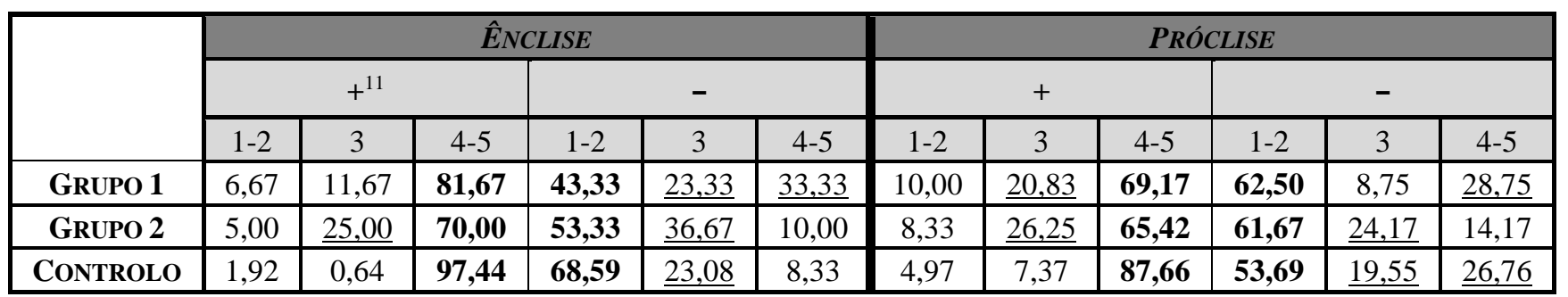

Tabela 4 - Taxas de aceitação/rejeição nos itens gramaticais e agramaticais (\%)

Por outro lado, não se verificou uma diferença assinalável entre os resultados sobre os clíticos reflexos e os não-reflexos, indicando que o estatuto do clítico não afeta os juízos dos informantes relativamente à sua colocação (Gráfico 2).

${ }^{11} \mathrm{O}$ símbolo “+” nesta tabela refere-se aos itens gramaticais, enquanto o símbolo “-” se relaciona com os itens agramaticais. 


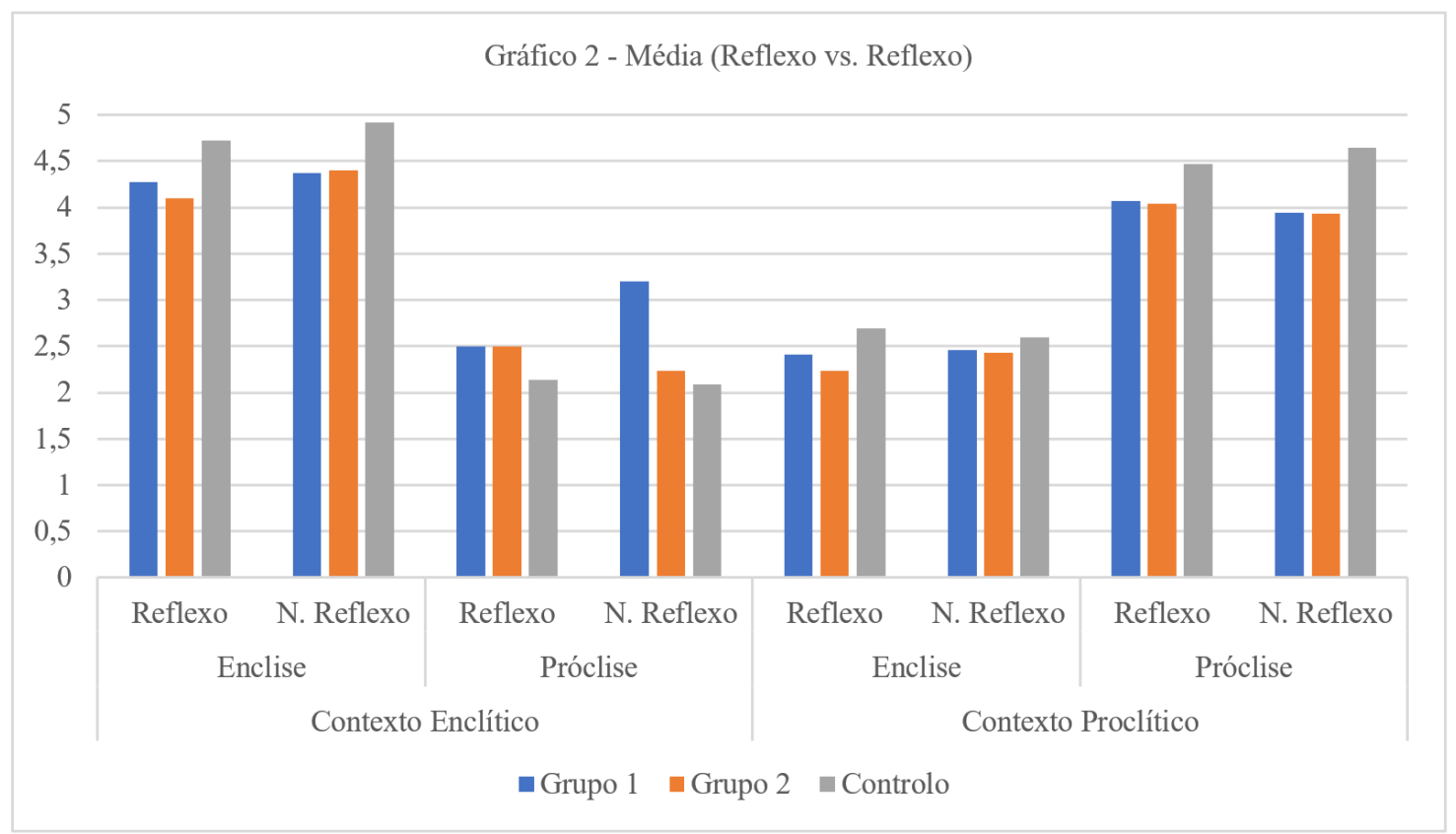

Ao proceder a uma análise detalhada dos dados dos participantes chineses nos diferentes contextos testados nesta tarefa (Gráficos 3-4), observaram-se indícios de um percurso de desenvolvimento da colocação proclítica dos clíticos, partilhado por ambos os grupos de participantes. Registou-se uma tendência de aquisição das propriedades em estudo: negação > advérbio > orações subordinadas adverbiais> quantificadores (sujeito).

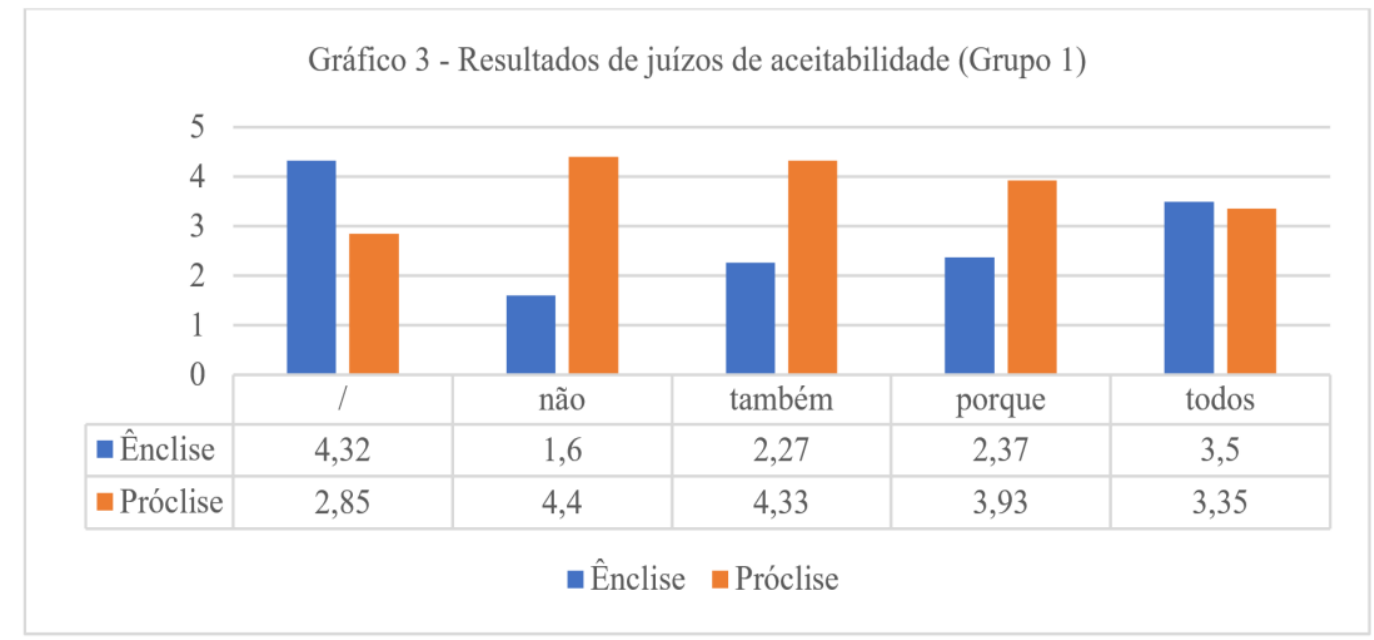




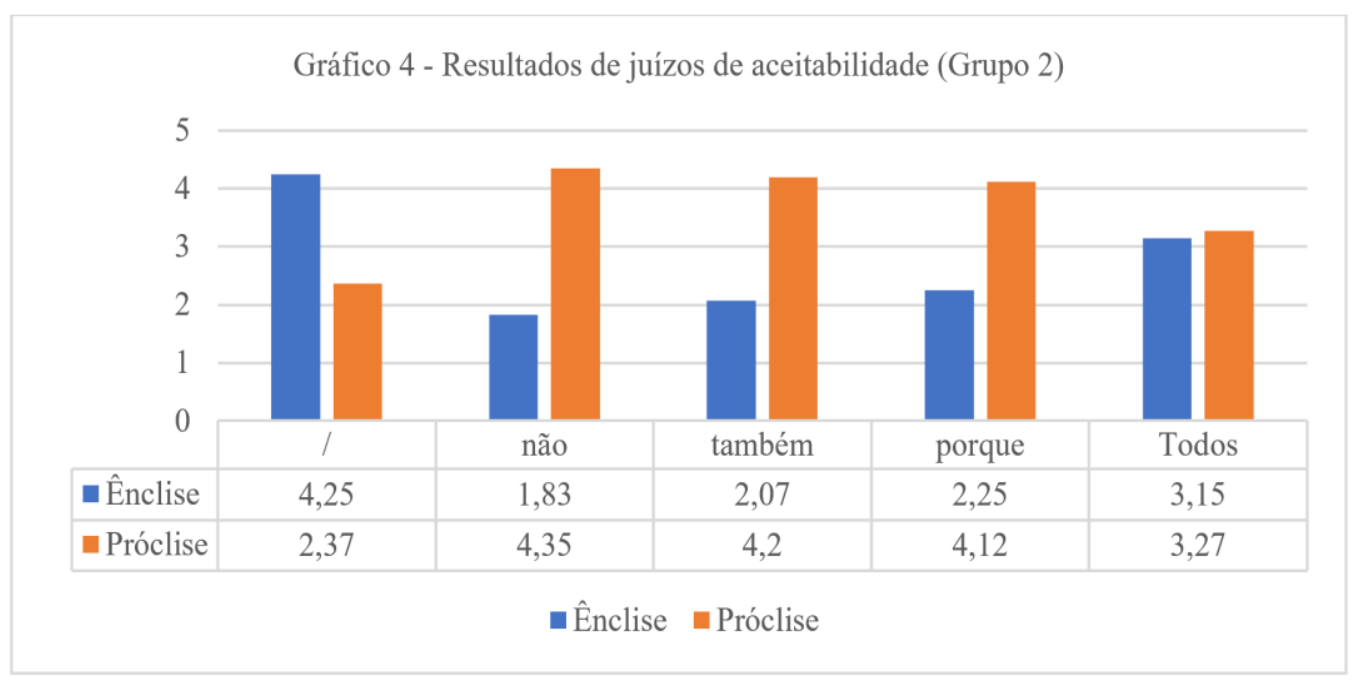

Esta tendência é semelhante à observada no grupo de controlo, como se ilustra no gráfico 5.

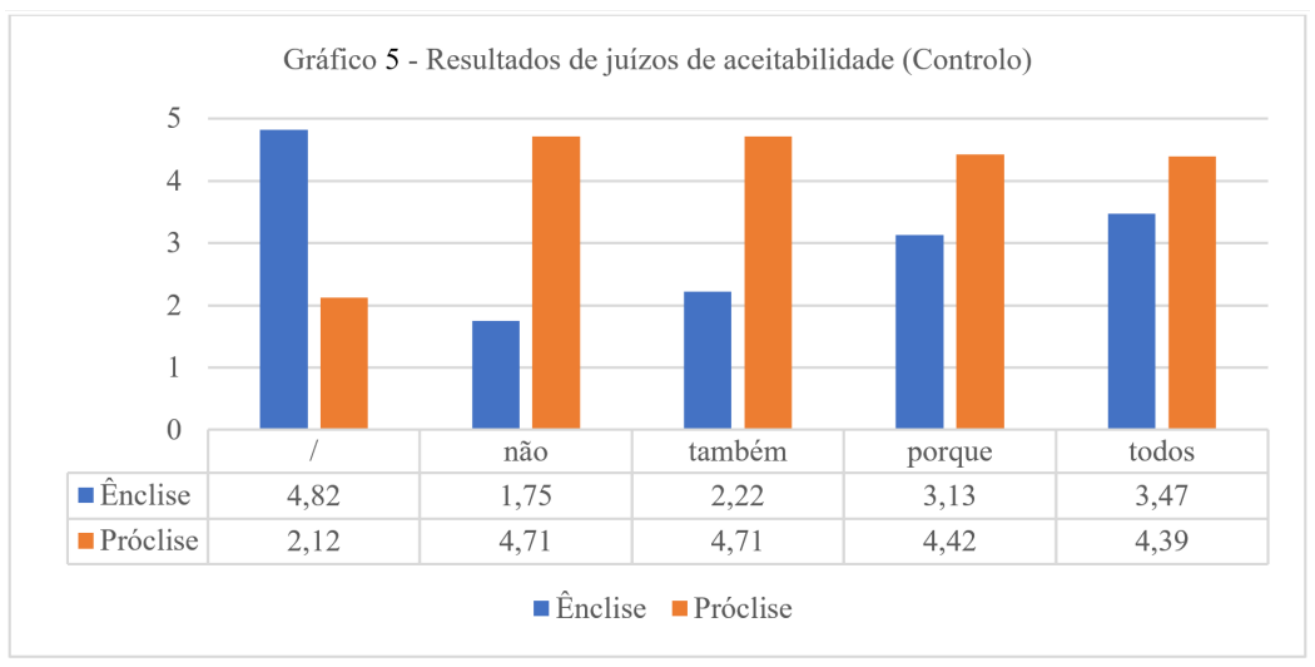

Esta observação relativamente às semelhanças na aquisição dos clíticos entre os três grupos foi confirmada também pelas taxas de respostas-alvo dos participantes nos diferentes contextos (Gráfico 6).

Vale a pena mencionar que as taxas de respostas-alvo dos três grupos de participantes nos contextos de ênclise são mais baixas do que as verificadas na maioria dos contextos de próclise. Isto poderia ter a ver com o facto de que os informantes, perante os itens em que os clíticos estão colocados inadequadamente nos contextos enclíticos, optaram muito mais pela pontuação "3", resposta que não foi incluída no cálculo de percentagens pela sua 
ambiguidade na interpretação (Tabela 4), em vez de escolherem as pontuações "1" ou "2". Também é possível ser relevante o facto de se juntarem aqui as respostas para os itens gramaticais e agramaticais e, como observado acima, os desempenhos dos participantes diferem nos dois tipos de itens.

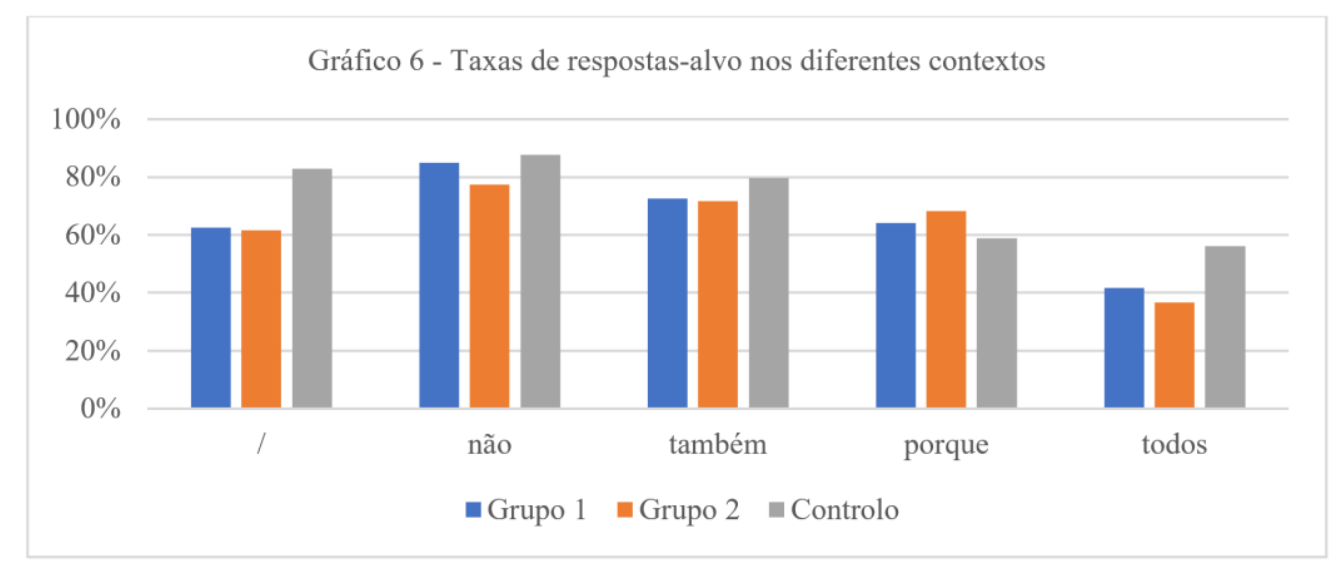

A fim de mostrar melhor o desempenho dos três grupos, recorremos a uma análise de regressão linear (Gráfico 7), com base nos juízos de cada participante na tarefa. Deu-se um ponto às respostas-alvo enquanto se atribuíram zero pontos às outras respostas, obtendo assim cada inquirido uma pontuação que representa o seu desempenho no teste. Foi observado que, relativamente aos controlos, os participantes chineses do grupo 1 tiveram sempre pontuações mais baixas; contudo, uma pequena parte dos participantes do grupo 2 obteve pontuações mais elevadas do que os falantes nativos de PE. 


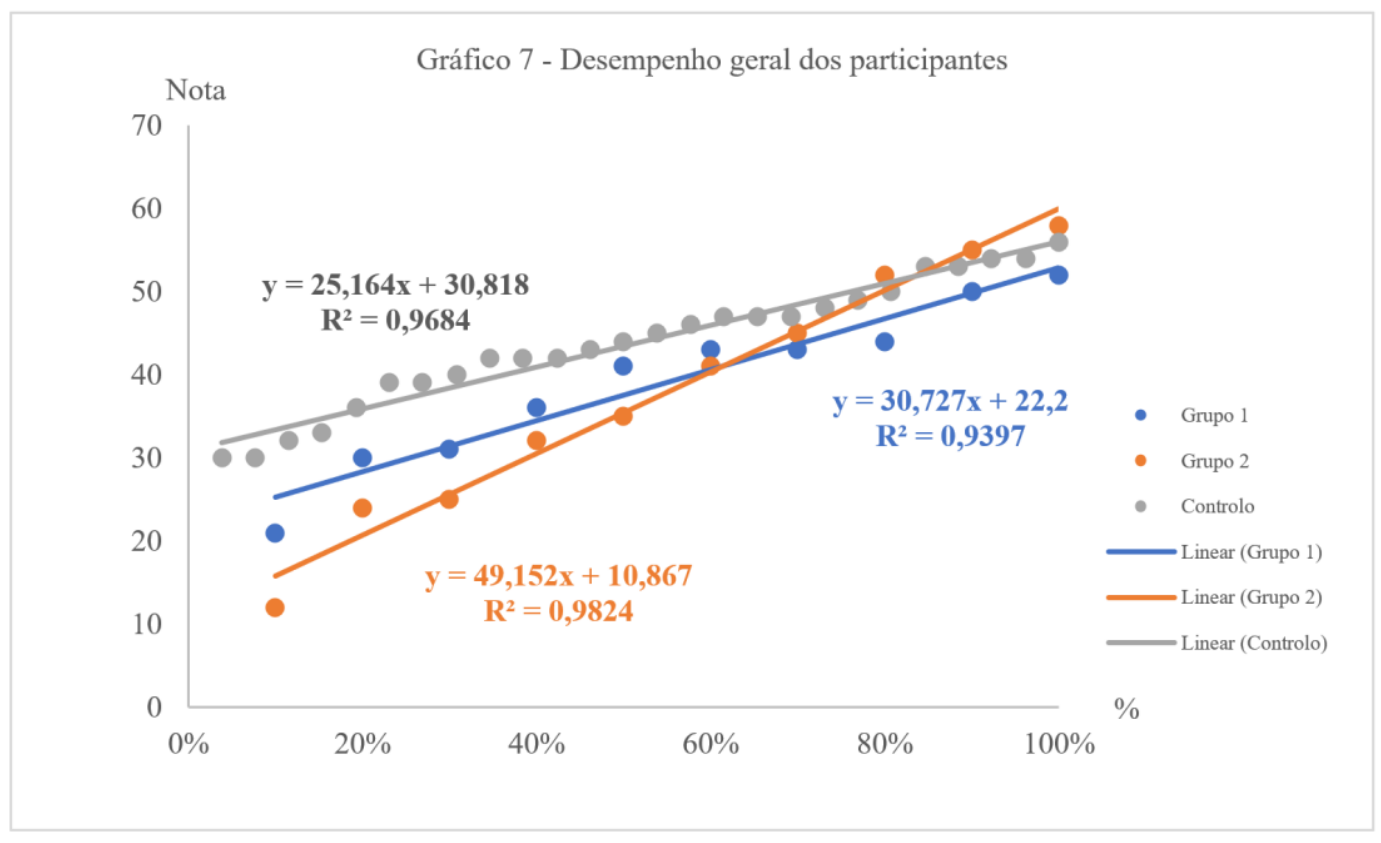

Para se verificar a existência de diferenças no desempenho entre os dois grupos chineses, foi realizada uma análise de variância (ANOVA) com fator único (Tabela 5). Os resultados da análise mostram que, do ponto de vista estatístico, não foi verificada diferença significativa entre os dois grupos chineses (valor $\mathrm{p}>0,05$ ), não se observando, assim, um efeito de desenvolvimento entre os alunos com menos tempo de aprendizagem de PE e os que têm mais tempo de aprendizagem.

Tabela 5 - Resultados da ANOVA do desempenho dos participantes

\begin{tabular}{|l|c|c|c|c|c|c|}
\hline & SQ & gl & MQ & F & valor P & F crítico \\
\hline G1-Controlo & 165,34 & 1,00 & 165,34 & 2,51 & 0,12 & 4,13 \\
\hline G2-Controlo & 258,67 & 1,00 & 258,67 & 2,55 & 0,12 & 4,13 \\
\hline G1-G2 & 7,20 & 1,00 & 7,20 & 0,05 & 0,83 & 4,41 \\
\hline
\end{tabular}

Com base nestas observações, procedeu-se a uma análise comparativa entre os resultados do presente estudo e os trabalhos já realizados sobre a aquisição da posição de pronomes clíticos em PE como L2.

Vimos que o nosso estudo confirmou algumas observações anteriormente registadas em $\mathrm{Gu}$ (no prelo), trabalho em que se investigou, através de uma tarefa de produção induzida, nos mesmos contextos, o estatuto e o desenvolvimento do conhecimento dos alunos chineses sobre a colocação dos pronomes clíticos em PE. Verificouse em ambos os estudos: a) melhor desempenho nos contextos enclíticos do que nos proclíticos, menos óbvio nos dados de juízos do que nos de produção; b) assimetrias no ritmo da aquisição do conhecimento sobre a posição dos 
clíticos, indiciando-se um percurso de desenvolvimento: negação > advérbio > oração subordinada finita > quantificador (sujeito).

No entanto, os dois trabalhos divergem a respeito de: a) assimetrias na colocação de clíticos reflexos e nãoreflexos, que se observam na produção, mas não nos juízos; b) efeito de desenvolvimento: foi verificado este efeito entre os dois grupos de alunos chineses (um com mais tempo de aprendizagem de PE do que o outro) nos dados de produção, mas não entre os dois grupos chineses nos resultados de juízos de aceitabilidade.

Foi realizada também a comparação entre os dados do presente estudo e os resultados de juízos de aceitabilidade obtidos em outros trabalhos de PE L2 e encontraram-se semelhanças, nomeadamente com falantes nativos de outras línguas românicas. Por exemplo, Madeira, Crispim e Xavier (2006) investigaram dois grupos de aprendentes L2 de PE (um com 7 meses de aprendizagem e tendo como L1 espanhol, italiano ou francês; e o outro com 2 anos de aprendizagem, constituído por falantes nativos de espanhol, catalão ou italiano) e observaram sequências de aquisição dos padrões de colocação dos clíticos semelhantes à observada no nosso trabalho (Gráfico 8).

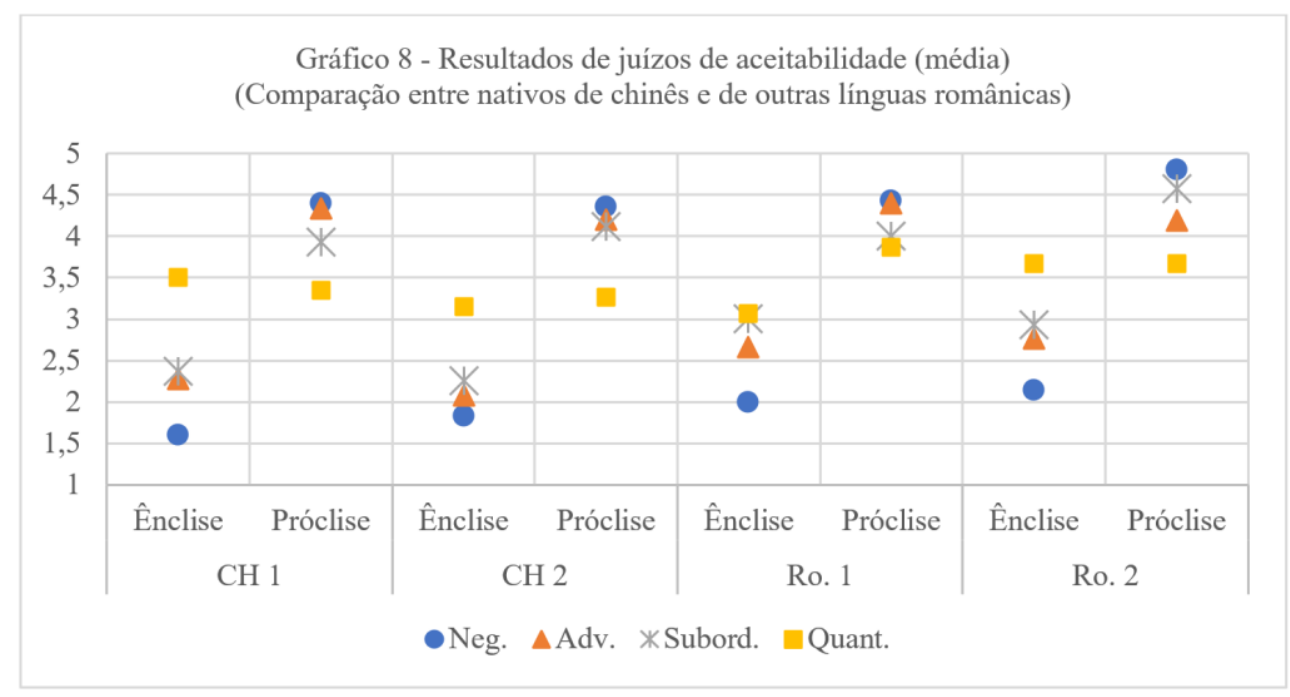

Esta sequência de aquisição também foi confirmada em Madeira \& Xavier (2009:16), com base nas taxas médias de respostas-alvo por contexto de um grupo de aprendentes L2 de PE (de nível elementar e tendo como L1 italiano, espanhol ou francês). A par disso, foram registadas ainda, nesse estudo, com o mesmo grupo de informantes, diferenças substantivas entre respostas-alvo para os itens gramaticais e os agramaticais, como no nosso estudo.

\section{Conclusões preliminares}

Através de uma pequena tarefa de juízos de aceitabilidade, neste trabalho, testaram-se dois grupos de aprendentes de PE, falantes nativos de chinês mandarim, sobre o seu conhecimento da posição dos pronomes clíticos acusativos em português. 
Com base nos dados obtidos, vimos que: 1) se observaram, em ambos os grupos, indícios da aquisição das propriedades-alvo, nomeadamente na distinção das condições que determinam a alternância entre ênclise e próclise, embora não sejam tão altas as taxas de acerto como as do grupo de controlo; 2) a ênclise parece ser mais fácil de adquirir do que a próclise, já que os informantes tenderam a apresentar melhor desempenho nos contextos enclíticos, mas este contraste não é grande; 3) foram verificadas assimetrias no desempenho dos participantes relativamente aos itens gramaticais e aos agramaticais, mostrando os informantes maior dificuldade na identificação dos itens agramaticais do que os gramaticais, indiciando que o conhecimento ainda não é estável; 4) registou-se um percurso da aquisição das condições proclíticas: negação > advérbio proclisador > oração subordinada finita > quantificador (sujeito).

Estas observações confirmaram alguns resultados registados por outros trabalhos em PE L2, nomeadamente com respeito à maior facilidade de aquisição da ênclise do que da próclise, apesar de tal ser menos óbvio nos dados de juízos do que nos de produção induzida (Gu, no prelo); à sequência de aquisição dos padrões de colocação dos clíticos, verificada também com outros falantes não nativos (Madeira, Crispim \& Xavier, 2006; Madeira \& Xavier, 2009; Gu, no prelo) e até com as crianças nativas (Costa, Fiéis \& Lobo, 2015); assim como às diferenças no desempenho para os itens gramaticais e os agramaticais (Madeira \& Xavier, 2009).

Vale a pena mencionar que existem ainda fenómenos observados em outros estudos, mas não no nosso trabalho, como, por exemplo, as assimetrias no desempenho para os pronomes reflexos e para os não-reflexos, a generalização da posição enclítica, ou o efeito de desenvolvimento no processo da aprendizagem. Os últimos dois poderão ter a ver com o facto de que os nossos participantes tinham já um mínimo de 3;5 anos de aprendizagem em média na altura de serem testados, etapa em que, possivelmente, este conhecimento já se encontrava desenvolvido. Também se deve reparar que se observou, entre os controlos, variação nos juízos para alguns contextos, tais como as orações subordinadas adverbiais e as frases com quantificadores, o que talvez indicie o fator de input linguístico ao qual estavam expostos os informantes estrangeiros.

Quanto às propostas teóricas acerca da possibilidade de aquisição dos traços não interpretáveis, embora não se tenha observado um efeito notável de desenvolvimento, as taxas relativamente altas de acerto conseguidas pelos informantes, por exemplo, no contexto das orações negativas, e o percurso de aquisição dos contextos de colocação dos pronomes clíticos partilhado entre os falantes nativos e não-nativos, poderiam servir, em certo sentido, como evidências da aquisição potencialmente bem-sucedida e do acesso à GU, assim, apoiando a proposta da Hipótese de Transferência Plena/Acesso Pleno.

Com base nestes dados e nas conclusões preliminares, continuaremos a exploração da temática, com o aumento do número de participantes e a inclusão de informantes com menos tempo de aprendizagem de português, e de novas questões de investigação inspiradas pelos resultados deste trabalho.

\section{Referências}

Brito, Duarte \& Matos (2003) Tipologia e distribuição das expressões nominais. In Gramática da língua portuguesa, editado por M. H. M. Mateus, I. Duarte \& I. H. Faria. Lisboa: Editorial Caminho, pp. 797-867.

Cardinaletti, A. \& M. Starke (1999) The typology of structural deficiency: On the three grammatical classes. In Clitics in the Languages of Europe, editado por H. van RIEMSDIJK. Berlin: Mouton de Gruyter, pp. 145-233. Costa, A. L. (2012) A mesóclise: uma espécie linguística em vias de extinção, ms. 
Costa, J. \& M. Lobo (2013) Aquisição da posição dos clíticos em português europeu. In Textos Selecionados, XXVIII Encontro Nacional da Associação Portuguesa de Linguística. Coimbra: APL, pp. 271-288.

Costa, J., Fiéis, A., \& Lobo, M. (2015) Input variability and late acquisition: Clitic misplacement in European Portuguese. Lingua 161, pp. 10-26.

Duarte, I., G. Matos \& I. Faria (1995) Specificity of European Portuguese clitics in Romance. In Studies on the Acquisition of Portuguese, editado por I. Faria \& M. J. Freitas. Lisboa: Associação Portuguesa de Linguística \& Edições Colibri, pp. 129-154.

Grosso, M. J. (1999) O Discurso metodológico do ensino do português em Macau a falantes de língua materna chinesa. Dissertação de doutoramento, Universidade de Lisboa.

Grüter, T. (2006) Object Clitics and Null Objects in the Acquisition of French. PhD Dissertation, McGill University, Montreal.

Guasti, M.T. (1993/94) Verb syntax in Italian child grammar: finite and nonfinite verbs. Language Acquisition 3(1), pp. 1-40.

Gu, W. J. (no prelo) Aquisição da posição dos pronomes clíticos de português europeu por falantes nativos de chinês. NOVALing: Textos Selecionados do XIII Fórum de Partilha Linguística. London: Ubiquity Press.

Lobo, M. (2013) Dependências Referenciais. In Gramática do Português, editado por Raposo, E. P., M. F. Bacelar, M. A. Mota, L. Segura \& A. Mendes. Lisboa: Fundação Calouste Gulbenkian, pp. 2177-2227.

Madeira, A., M. L. Crispim \& M. F. Xavier (2006) Clíticos pronominais em português L2. In APL - Textos Selecionados. XXI Encontro Nacional da Associação Portuguesa de Linguística. Lisboa: Colibri, pp. $495-510$.

Madeira, A. \& M. F. Xavier (2009) The Acquisition of Clitic Pronouns in L2 European Portuguese. In Minimalist Inquiries into Child and Adult Language Acquisition: Case Studies across Portuguese, editado por A. Pires \& J. Rothman. Berlin/New York: Mouton de Gruyter, pp. 273-299.

Madeira, A. (2017) Aquisição de língua não materna. In Aquisição de língua materna e não materna: Questões gerais e dados do português (Textbooks in Language Sciences 3), editado por Freitas, M. J. \& A. L., Santos. Berlin: Language Science Press, pp. 305-330.

Mai, R. (2006) Aprender português na China: o curso de licenciatura em Língua e Cultura Portuguesas da Universidade de Estudos Internacionais de Xangai: estudo de caso. Dissertação de mestrado, Universidade de Aveiro.

Marinis, T. (2000) The acquisition of clitic objects in Modern Greek: Single clitics, clitic doubling, clitic left dislocation. ZAS Papers in Linguistics 15, pp. 259-281.

Martins, A. M. (2013) A posição dos pronomes pessoais clíticos. In Gramática do Português, editado por Raposo, E. P., M. F. Bacelar, M. A. Mota, L. Segura \& A. Mendes. Lisboa: Fundação Calouste Gulbenkian, pp. 22312302.

Rosário, M. (1997) A aquisição dos clíticos em português como língua estrangeira: o papel da língua materna. Dissertação de mestrado em Linguística, Universidade de Lisboa.

Santos, F. (2002) Os pronomes pessoais átonos no português europeu. Descrição de problemas que ocorrem no $3^{\circ}$. ciclo e proposta de atividades didáticas. Dissertação de mestrado, Universidade de Lisboa.

Tsimpli, I. M. \& M. Dimitrakopoulou (2007) The Interpretability Hypothesis: Evidence from wh-interrogatives in second language acquisition. Second Language Research, 23, pp. 215-242.

Wexler, K., Gavarrò, A. \& Torrens, V. (2004) Feature checking and object clitic omission in child Catalan and Spanish. In Romance Languages and Linguistic Theory 2002, editado por Bok-Bennema, R., Hollebrandse, B., Kampers-Manhe, B., Sleeman. Amsterdam: John Benjamins, pp. 253-268. 